\title{
Bronchial responsiveness to histamine in wheezy infants
}

\author{
ANNE PRENDIVILLE, SALLY GREEN, MICHAEL SILVERMAN \\ From the Department of Paediatrics and Neonatal Medicine, Royal Postgraduate Medical School, \\ Hammersmith Hospital, London
}

ABSTRACT Little is known about airway responsiveness in infancy. The bronchial response to is incremental doses of nebulised histamine (to a maximum dose of $8 \mathrm{~g} / \mathrm{l}$ ) was measured in 11 wheezy $\mathrm{N}$

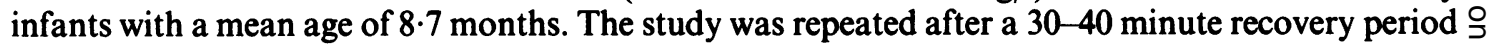
in seven infants and again on a separate day in 10. The index of response was the provoking $\overrightarrow{7}$ concentration of histamine that produced a $30 \%$ fall in the maximum expiratory flow at functional $\mathbb{D}$ residual capacity $\left(\mathrm{PC}_{30}\right)$, taken from partial forced expiratory flow-volume curves produced in a pressure jacket. Nine of 11 infants had a $\mathrm{PC}_{30}$ of less than $8 \mathrm{~g} / \mathrm{l}$. The response was consistent between tests in both the nine responders and the two who failed to respond at $8 \mathrm{~g} / \mathrm{l}$. The $\mathrm{PC}_{30}$ was $\vec{\bullet}$ lower in infants with more severe baseline airway obstruction. Spontaneous recovery after challenge $\stackrel{\infty}{v}$ was complete in 30 minutes in seven of eight infants studied. The highest doses of histamine caused changes in the configuration of the flow-volume curves and symptomatic cough and wheeze in addition to a change in forced flow rates. This study provides clear evidence of intrathoracic airway responsiveness to histamine in infancy.

The concept of bronchial responsiveness has played an important part in elucidating the pathophysiology of asthma in older children ${ }^{12}$ and adults. ${ }^{34}$ Very little is known, however, about airway function in wheezy infants. The repeated failure of wheezy infants under 18 months to respond to nebulised sympathomimetic agents, ${ }^{5}$ in contrast with older subjects, suggests that different mechanisms may operate in the infant airway.

Two recent studies have shown that the infant airway can respond to an inhaled bronchoconstrictor agent, ${ }^{67}$ suggesting that wheezy infants may have the capacity to develop bronchoconstriction in a similar way to older children. Unfortunately, both these studies relied on measurements of resistance that included the upper airway (nasal passages and larynx) as well as the intrathoracic airways. As the nasal passages account for about half of the total airway resistance in normal infants, ${ }^{8}$ an index of responsiveness that includes upper airway changes is likely to be a poor reflection of true bronchial

Address for reprint requests: Dr $M$ Silverman, Department of Paediatrics and Neonatal Medicine, Hammersmith Hospital, London W120HS.

Accepted 30 September 1986 responsiveness. Moreover, nebulised bronchoconstrictor or bronchodilator agents often have direct effects on the upper airway itself, ${ }^{9}$ rendering the measurement of even more dubious value.

We have adapted the technique recently described for measuring partial expiratory flow-volume (PEFV) curves in infancy. ${ }^{1011}$ In theory, provided that flow limitation is achieved, this technique should provide $\frac{3}{3}$ information on the function of the intrathoracic airways, independently of wide variations in upper air- $\frac{\text { O }}{3}$ way resistance. The method has been used to study intrathoracic airway function in wheezy infants, ${ }^{1213}$ 의 and in one study of normal infants the airway $\frac{D}{0}$ response to breathing cold, dry air was reported briefly. ${ }^{14}$

Because infants are usually nose breathers, we decided to use a short lived pharmacological bronchoconstrictor stimulus, nebulised histamine, $\omega$ rather than cold air or ultrasonically nebulised distilled water, neither of which would be likely to reach ${ }_{C}$ the lower airway in effective amounts. We chose hista- $\underset{\mathscr{D}}{\overparen{D}}$ mine rather than methacholine because of its briefer ? physiological effect. ${ }^{15}$ The continuous tidal breathing $\frac{0}{0}$ method, ${ }^{16}$ which has been shown to be highly $\underset{\mathbb{D}}{ }$ reproducible in older children, ${ }^{17}$ is the basis of the $\odot$ technique we have developed for measuring bronchial $\triangle$ responsiveness in infants. 
Methods

\section{SUBJECTS}

Eleven recurrently wheezy infants were studied at a mean age of 8.7 months (SD 3.1, range 3-13). Nine of the infants had a first degree family history of atopic disease. None had had acute bronchiolitis. Five infants had a history of eczema and one was ventilated for eight days in the newborn period for respiratory distress syndrome. Seven of the infants had parents who smoked.

The duration of their history of wheezing varied from one to 10 months and attacks were intermittent, the time interval between attacks varying from 24 hours to four weeks. The infants were free of wheeze at the time of testing. Sedation with chloral hydrate $(100 \mathrm{mg} / \mathrm{kg}$ orally) was given 30 minutes before each test. No infant had received any other drug within 24 hours of a test.

The studies formed part of an investigation of airway function in infants, for which the ethics committee's approval and parental consent were obtained.

\section{EQUIPMENT}

When fast asleep, the infant was placed in a whole body plethysmograph incorporating a servo controlled breathing system maintained at $37^{\circ} \mathrm{C} .{ }^{18}$ Baseline measurements of thoracic gas volume (TGV) and inspiratory airway resistance (Raw) were then obtained by previously described techniques. ${ }^{19}$ Their multiple (specific airway resistance, sRaw) was computed as a measure of baseline airway calibre. ${ }^{20}$ Recent evidence suggests that individual values of TGV (and therefore Raw) may not always be reliable in infants with airway obstruction. ${ }^{21}$

To measure PEFV curves, the infant was placed in a polythene jacket extending from the shoulders to the upper thighs but cut away at the neck to avoid pressure on the trachea. ${ }^{11}$ The double thickness anterior part covering the abdomen and chest was inflatable through a wide bore $(20 \mathrm{~mm})$ connection. Jacket inflation pressures of $30-40 \mathrm{~cm} \mathrm{H}_{2} \mathrm{O}$ pressure were achieved within 100 milliseconds by throwing open a three way tap (internal diameter $22 \mathrm{~mm}$ ) connecting a pressurised 60 litre tank to the pressure jacket. Timing of jacket inflation at end inspiration was achieved by watching the flow and volume signals displayed on an oscilloscope. The jacket pressure was measured by a transducer (SE Laboratories).

Flow was measured with a heated screen pneumotachograph (diameter $19 \mathrm{~mm}$ and linear to at least $401 \mathrm{~min}^{-1}$ ) with an accompanying flow transducer (Validyne MP 45). This was attached to a firm face mask (Rendell-Baker), which was sealed around the nose and mouth with silicone putty. The flow signal was electronically integrated to give volume and these signals and also the jacket pressure signal were recorded by ultraviolet chart recorder (SE Laboratories). Flow and volume signals were displayed continuously on a large oscilloscope. In addition, the flow signal was fed via an A-D converter (sampling rate $100 \mathrm{~Hz}$ ) into an Apple 11 microcomputer for digital integration. From these data calibrated flow-volume curves were produced later.

Nebulised histamine and control saline solutions were administered by Turret nebuliser (Medic-Aid). The nebulisers had a measured output of $0.21 \mathrm{ml} \mathrm{min}^{-1}$ at $61 \mathrm{~min}^{-1}$ air flow. Repeatability of output was measured as the standard deviation and for different nebuliser units measured five times each ranged from 0.007 to $0.017 \mathrm{ml} \mathrm{min}^{-1}$.

\section{ANALYSIS}

From the chart record of flow, volume, and jacket pressure, we determined tidal volume, frequency of breathing, and maximum flow rate at functional residual capacity extrapolated from the previous two or three tidal breaths (VmaxFRC). ${ }^{11}$

The within patient coefficient of variation of VmaxFRC in wheezy infants is $13 \%,{ }^{11}$ so the provoking concentration of histamine that caused a $30 \%$ drop in VmaxFRC $\left(\mathrm{PC}_{30}\right)$ was used as the index of bronchial responsiveness to histamine. Reference values for sRaw were derived from the data of Stocks, ${ }^{8}$ with deadspace correction. There are no adequate reference values for VmaxFRC in postneonatal infants. As a guide, values obtained previously by the author were used, ${ }^{11}$ with infant length rather than lung volume as the independent variable.

\section{DESIGN OF STUDIES}

Studies were performed at about the same time on two separate days within a five day period. After baseline measurements of specific airway resistance, six to eight PEFV curves were obtained at $\mathbf{3 0}$ second intervals as described above.

Nebulised saline at room temperature was then administered by directing the output of the nebuliser over the nose and mouth of the sleeping infant for one minute. A further set of four PEFV curves was obtained. Doubling concentrations of histamine phosphate solution were then administered for one minute periods at five minute intervals, starting at a concentration of $0.25 \mathrm{~g} / \mathrm{l}$. A set of four PEFV curves was obtained after each dose. The curves were continuously viewed on the oscilloscope either until a response to histamine was judged to have occurred from the change of shape of the PEFV curve or until a concentration of histamine of $8 \mathrm{~g} / \mathrm{l}$ had been reached, whichever occurred sooner. Over the next 30 minutes repeated sets of PEFV curves were obtained 
Individual lung function data for the 11 infants

\begin{tabular}{|c|c|c|c|c|c|c|c|c|c|c|}
\hline \multirow[b]{3}{*}{$\begin{array}{l}\text { Patient } \\
\text { No }\end{array}$} & \multirow[b]{3}{*}{$\begin{array}{l}\text { Age } \\
\text { (months) }\end{array}$} & \multirow[b]{3}{*}{$\begin{array}{l}\text { Length } \\
(\mathrm{cm})\end{array}$} & \multicolumn{5}{|l|}{ Study day $l$} & \multicolumn{3}{|l|}{ Study day 2} \\
\hline & & & \multirow{2}{*}{$\begin{array}{l}\text { Baseline } \\
\text { sRaw } \\
\text { (x reference) }\end{array}$} & \multicolumn{2}{|l|}{ Test 1} & \multicolumn{2}{|l|}{ Test 2} & \multirow{2}{*}{$\begin{array}{l}\text { Baseline } \\
\text { sRaw } \\
\text { (x reference) }\end{array}$} & \multicolumn{2}{|l|}{ Test 3} \\
\hline & & & & $\begin{array}{l}V \max F R C \dagger \\
(\%)\end{array}$ & $\begin{array}{l}P C_{30} \\
(g / l)\end{array}$ & $\begin{array}{l}V_{\max }(\%) \\
(\%)^{\prime}+\end{array}$ & $\begin{array}{l}P C_{30} \\
(g / l)\end{array}$ & & $\underset{(\%)}{V \max F R C \dagger}$ & $\begin{array}{l}P C_{30} \\
(g / l)\end{array}$ \\
\hline $\begin{array}{r}1 \\
2 \\
3 \\
4 \\
5 \\
6 \\
7 \\
8 \\
9 \\
10 \\
11\end{array}$ & $\begin{array}{r}8 \\
6 \\
3 \\
5 \\
12 \\
10 \\
13 \\
8 \\
9 \\
13 \\
9\end{array}$ & $\begin{array}{l}73 \\
69 \\
62 \\
61 \\
71 \\
74 \\
78 \\
67 \\
77 \\
74 \\
72\end{array}$ & $\begin{array}{l}8.7 \\
2.8 \\
0.7 \\
2.3 \\
1.2 \\
1.4 \\
1.9 \\
1.2 \\
\frac{1}{1.2} \\
1.1\end{array}$ & $\begin{array}{r}58 \\
49 \\
50 \\
84 \\
50 \\
103 \\
91 \\
52 \\
29 \\
65 \\
137\end{array}$ & $\begin{array}{l}1.6 \\
0.53 \\
0.23 \\
2.8 \ddagger \\
2.2 \$ \\
1.7 \\
7.9 \\
0.4 \\
0.48 \\
>8 \\
>8\end{array}$ & $\begin{array}{r}67 \\
36 \\
46 \\
65 \\
93 \\
117 \\
- \\
= \\
48 \\
-\end{array}$ & $\begin{array}{c}2.0 \\
0.33 \\
0.33 \\
0.95 \\
0 \cdot 17 \\
1.5 \\
- \\
- \\
>- \\
-\end{array}$ & $\begin{array}{l}5.2 \\
6.6 \\
2.3 \\
1.6 \\
1.3 \\
5.7 \\
2.6 \\
2.0 \\
9.6 \\
1.4\end{array}$ & $\begin{array}{r}44 \\
57 \\
32 \\
82 \\
95 \\
-113 \\
32 \\
33 \\
31 \\
209\end{array}$ & $\begin{array}{l}0.49 \\
0.38 \\
0.78 \\
0.85 \\
0.48 \\
- \\
0.40 \\
1.9 \\
0.42 \\
>8 \\
>8\end{array}$ \\
\hline Mean* & $\begin{array}{r}8 \cdot 7 \\
(3 \cdot 1)\end{array}$ & $\begin{array}{l}71 \\
(5 \cdot 3)\end{array}$ & $\begin{array}{l}1 \cdot 7 \\
(0 \cdot 45-6 \cdot 5)\end{array}$ & $\begin{array}{l}63 \\
(28-144)\end{array}$ & & $\begin{array}{c}63 \\
(43-92)\end{array}$ & & $\begin{array}{l}3 \cdot 0 \\
(0 \cdot 8-11 \cdot 5)\end{array}$ & $\begin{array}{l}59 \\
(17-204)\end{array}$ & \\
\hline
\end{tabular}

*Values in parentheses are SDs or confidence limits (for log normal data).

†Expressed as a percentage of the approximate reference value, based on body length. ${ }^{11}$

If maximum VmaxFRC is used the corrected $\mathrm{PC}_{30}$ is 1.9 .

If maximum value of $\mathrm{V}$ maxFRC is used the corrected $\mathrm{PC}_{30}$ is 0.45

**Awoke before maximum dose given.

sRaw - specific airway resistance; VmaxFR - maximum expiratory flow at functional residual capacity; $\mathrm{PC}_{30}$-provoking concentration of histamine that produced a $30 \%$ fall in VmaxfrC.

at five minute intervals, so that the rate of recovery could be monitored. The histamine challenge test was repeated on one of the two test days where continued slumber made this possible (7/11 occasions). The repeat on the other test day was used for a pharmacological study not reported here.

For each histamine challenge test the $\mathrm{PC}_{30}$ was calculated from the graph of log histamine concen-

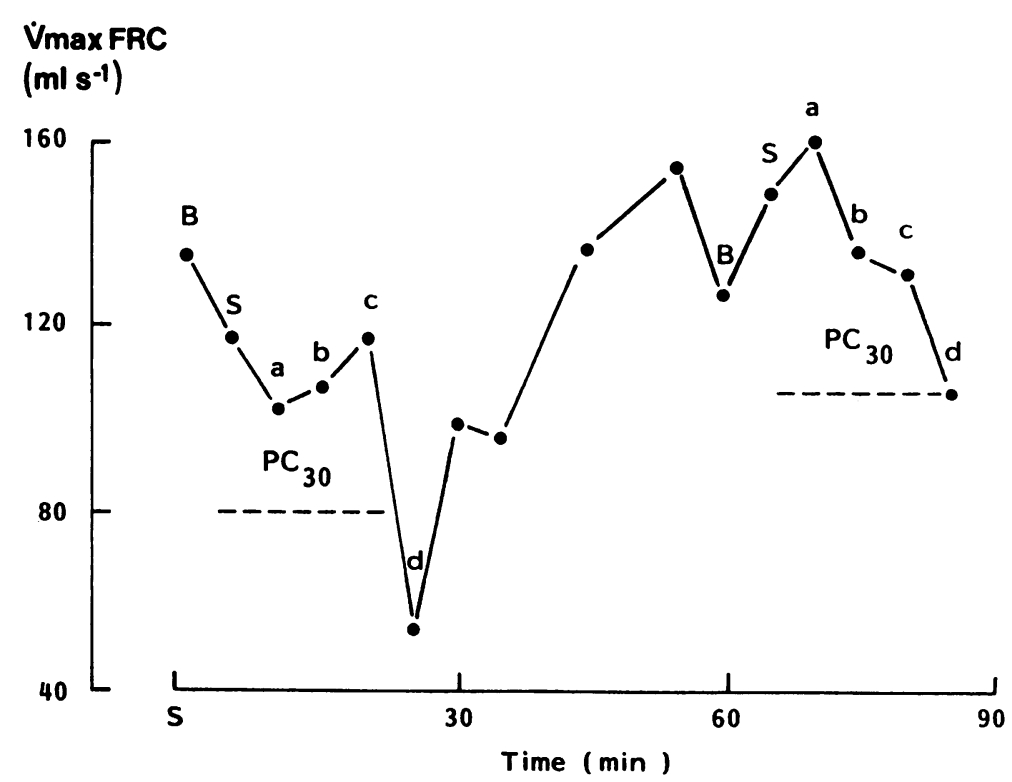

Fig 1 Time course of a set of two histamine challenge tests carried out on one child (patient 1 , tests 1 and 2-see table). Each point represents the mean of 3-8 values of $\dot{V}$ maxFRC. Each step is represented as follows: $B$-baseline value before testing; $S$ - value after control saline inhalation; $a$-'d histamine solutions at doubling concentrations from 0.25 to $2 \mathrm{~g} / \mathrm{l}$. $\mathrm{PC}_{30}$ values are indicated. Abbreviations as in table. 


\section{Vmax FRC}

(\%post-

saline value)
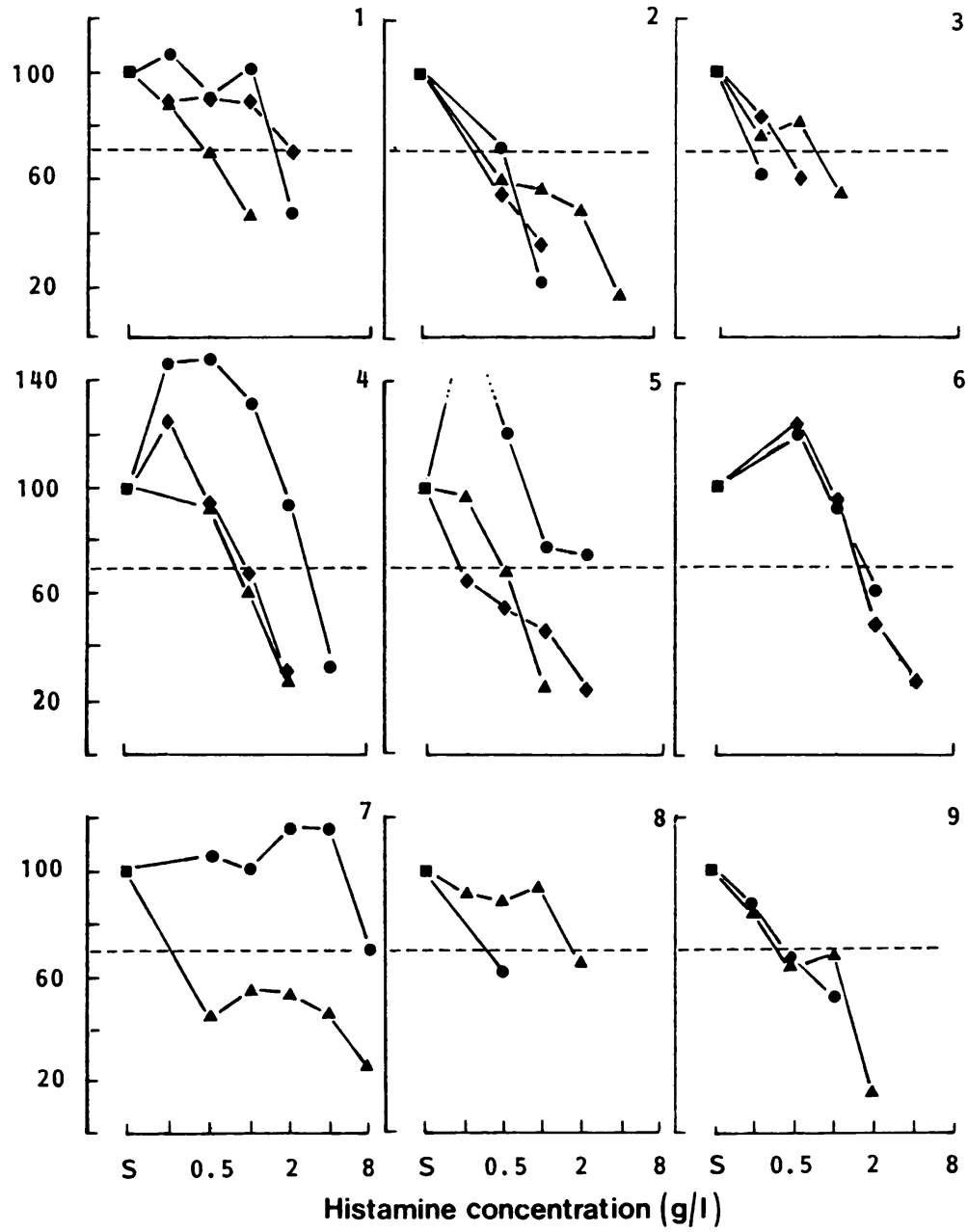

Fig 2 Individual histamine response curves for the nine responders. test 1; 1 test 2; $\Delta$ test 3 (see table). Dashed line indicates $30 \%$ fall in VmaxFRC. Abbreviations as in table.

tration against change in $\dot{V}$ maxFRC by interpolation. In two of the tests (fig 2) a $30 \%$ fall in VmaxFRC was not quite achieved; in those tests the curve was extrapolated to give a $\mathrm{PC}_{30}$ value.

\section{Results}

Baseline values of sRaw were moderately raised on both study days (table). Mean baseline values of VmaxFRC were $63 \%$ and $59 \%$ of previous reference values on days 1 and 2. An example of change in VmaxFRC during the full sequence of tests on one day in one infant is shown in figure 1.

$\mathrm{PC}_{30}$

Nine of the 11 infants had a $\mathrm{PC}_{30}$ within the range $0 \cdot 23-8 \mathrm{~g} / \mathrm{l}$ (table). The initial dose-response curves for these nine infants (fig 2 ) showed some variation. The geometric mean $\mathrm{PC}_{30}$ of the nine responders was $1 \cdot 13 \mathrm{~g} / 1$ during the first histamine challenge test. 


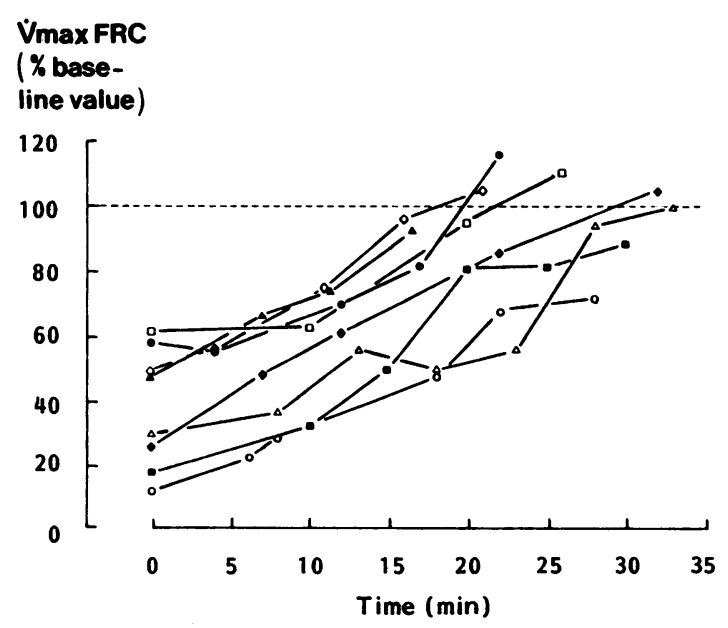

Fig 3 Rate of recovery from histamine induced bronchial obstruction. The mean recovery rates from tests 1 and 3 are given for seven of the nine responders. Recovery data were available for only one test from one further subject, and non-existent for another because of arousal. Abbreviations as in table.

The time course of recovery of VंmaxFRC was observed in the eight infants who remained asleep (fig 3). Seven infants recovered to within $20 \%$ of baseline VmaxfRC within 30 minutes. Recovery time appeared to be longer the greater the fall from the initial V́maxfre (fig 3). The mean VंmaxFRC after recovery was identical to the baseline value (table).

Seven infants remained asleep and had a further
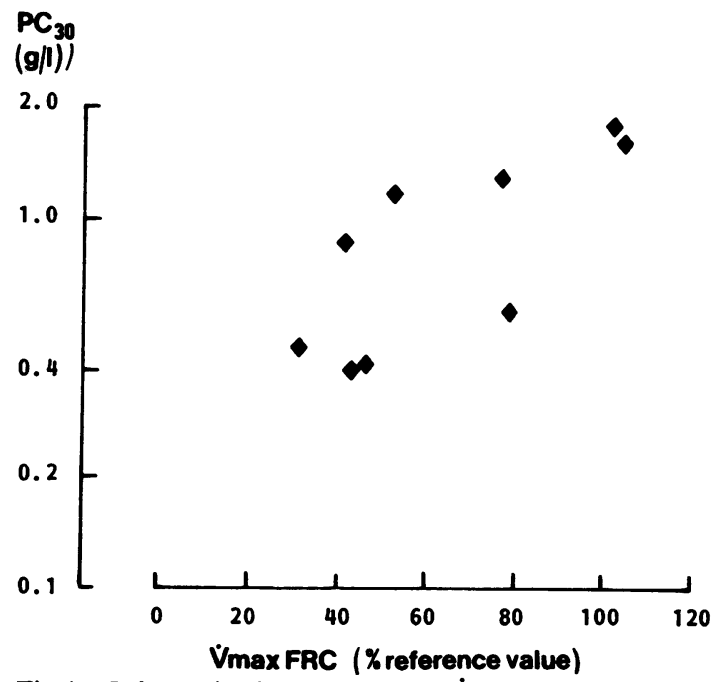

Fig 4 Relationship between baseline $\dot{V}$ maxFRC and bronchial responsiveness for responders, with the mean value for each subject. (Note the log scale for $P C_{30}$.) Abbreviations as in table. histamine challenge performed after recovery from the first test; five had values of $\mathrm{PC}_{30}$ on rechallenge that were within one histamine dilution of their $\mathbf{P C}_{30}$ during the first challenge (table), including one infant who failed to respond on both occasions. There was a tendency for $\mathrm{PC}_{30}$ to be lower in the second test. Two infants had poorly reproducible values of $\mathrm{PC}_{30}$ on rechallenge on the same day (Nos 4 and 5 - see table). Both infants had an increase in VmaxFRC after the first dose of histamine during the first challenge (fig 2), and when the maximum value of $\dot{V}$ maxrRC was taken as baseline for calculating a $30 \%$ fall the difference in $\mathrm{PC}_{30}$ became much less (see footnotes to the table). The $95 \%$ confidence interval for $\mathrm{PC}_{30}$ within the same day, for individual patients, was 1.8 doubling concentrations.

There was a significant correlation between individual mean values of baseline $\dot{V}$ maxFRC and $\log \mathbf{P C}_{30}$ (fig 4; $t=3.6 ; \mathrm{p}=0.009$ ). For individual patients, however, there was no consistent relationship between changes in baseline $\mathrm{V}$ maxFRC and change in $\mathrm{PC}_{30}$.

Ten infants were rechallenged with histamine on a second day within five days of the first. The two infants who failed to respond to histamine $8 \mathrm{~g} / 1$ on the first day also failed to respond on the second. All eight infants who responsed to histamine on the first test day responded on the second day, but the values of $\mathrm{PC}_{30}$ were less reproducible than within a day (table). The corresponding $95 \%$ confidence interval was 4.5 doubling concentrations.

Six of the nine reactors developed cough or obvious wheeze at the highest or penultimate concentration of histamine given. Three were symptom free despite appreciable changes in VmaxfRC. There was a tendency for breathing frequency to increase at the highest concentrations of histamine, but this was not a consistent finding.

\section{Discussion}

This study has shown that wheezy infants develop airway responsiveness to much the same concentrations of histamine as older asthmatic subjects ${ }^{217}$ and that the response is of similar duration. ${ }^{15}$ The pressure jacket used to produce partial expiratory flow-volume (PEFV) curves provided a practical and simple means of measuring the airway response to histamine independently of upper airway change in these nose breathing subjects. This technique provides for the first time a measure of responsiveness of the intrathoracic airways to histamine in infancy. There are two aspects that merit discussion. Firstly, the measurement and interpretation of PEFV curves in infants as a means of studying intrathoracic airway changes is relatively untested. Secondly, the nature 
and clinical significance of the response to histamine in the absence of control data is clearly of great importance. These aspects will be discussed separately.

PEFV CURVES AND $\dot{V}_{\max }$ RC

Infant PEFV curves produced with the pressure jacket have many of the physiological and clinical characteristics of flow-volume curves generated by voluntary effort in older subjects, despite the many differences: supine posture, tidal breathing, nasal breathing, and being asleep. ${ }^{111}$ Expiratory flow limitation occurs in both normal and wheezy infants under conditions used in this study. ${ }^{11}$ Under baseline conditions, before exposure to the histamine, it seems reasonable to suppose that flow rates derived from the PEFV curves reflect conditions in the intrathoracic airways. Exposure to nebulised histamine, however, may have several physiological effects that could upset this interpretation. Since we related maximum expiratory flow to the level of FRC, determined from the previous three regular tidal breaths, and not to an absolute value of lung volume, any increase in the level of FRC during the histamine inhalation procedure could influence the apparent response. Increased elastic recoil of the lung at higher lung volumes will tend to increase the value of VmaxFRC. An increase in lung volume resulting from histamine induced airway obstruction, exacerbated by the increase in breathing frequency that often accompanied the higher concentrations of histamine, would lead to a progressive overestimation of V́maxFRC with increasing concentrations. This may be clinically disadvantageous since the true threshold concentration must be greatly exceeded before any recognisable change in the PEFV curve is detectable - hence the rather extreme responses to histamine illustrated in figure 3. The underestimate in VmaxFRC should, however, preclude false positive values (that is, falsely low values) of $\mathrm{PC}_{30}$.

The measurement of lung volume in the infant plethysmograph is neither rapid enough nor sufficiently accurate $^{21}$ in the presence of airways obstruction to permit allowance for changes in FRC to be made during the course of a histamine challenge test. The great advantage of the pressure jacket technique is its rapidity, which minimises the chance of underestimating airway responsiveness owing to the relatively short duration of histamine induced airway obstruction (fig 3).

Nebulised histamine is known to cause narrowing of the nasal and laryngeal sections of the upper airway. ${ }^{9223}$ A disproportionate upper airway effect could, by imposing a high extrathoracic resistance, limit the intrathoracic airflow and airway pressure gradient to such an extent that flow limitation is no longer achieved at FRC. We have no direct evidence on this point. We found changes in the shape of the PEFV curves, however, in parallel with changes in VmaxFRC, consistent with intrathoracic flow limitation. Nor did the concave shape of the curve suggest that the limitation was due to inspiratory effort by the infants in response to inflation of the jacket; this would cause the curve to be truncated and convex in shape. ${ }^{11}$

Finally, histamine induced reductions in lung compliance, independent of airway effects, have been noted $^{24}$ and could have had major effects on $\dot{V}$ maxFRC. As we have no independent measure of lung compliance, there is no way to distinguish such potential effects from what appears to be the more likely effect: that changes in VmaxFRC in response to histamine were due to change in intrathoracic airway function.

A fall of maximum flow at $25 \%$ of vital capacity (Vmax $25 \% \mathrm{VC}$ ) of $80 \%$ is equivalent to a change in FEV 1 of about $40 \%$ in older asthmatic children during challenge, so the changes in VmaxFRC that we induced (fig 3) were of the same order as those seen in older subjects. It might be possible, by some form of shape analysis, to derive a more sensitive index from the PEFV curve than the VmaxFRC, ${ }^{25} 26$ so that the histamine challenge could be terminated at a lower concentration of histamine.

The apparently low baseline value of VmaxFRC for some subjects (table) may at first sight appear surprising. The sort of guideline used for challenge tests in older asthmatic subjects (FEV $>50 \%$ ), however, means that many tests are performed with $\dot{\mathrm{V}} \max 25 \% \mathrm{VC}$ values of $20-30 \%$ of reference values.

\section{RESPONSE TO HISTAMINE}

The administration of nebulised histamine by directing the jet over the sleeping infant's nose and mouth is clearly an inexact art. By using a high flow rate and by nebulising for one minute, we hoped to eliminate breath to breath variations in dose. A large proportion of the nebulised drug must nevertheless have settled in the nasal passages, and it may seem surprising that any degree of reproducibility was obtained. In a comparison between face mask and mouthpiece administration of histamine in adult subjects, no difference in $\mathbf{P C}_{20}$ was found and the reproducibility of the face mask technique was minimally better. ${ }^{27}$

Other workers have used carbachol as the bronchoconstrictor agent. ${ }^{67}$ The potentially long duration of effect of this drug is its main drawback, although its more precise mode of action is an advantage. The action of histamine on the lower airway is likely to be a complex mixture of vascular effects on the airway epithelium, indirect (vagally mediated) and direct effects on airway smooth muscle, pulmonary vascular 
changes, and reflex effects from the upper airway. Its main advantage is the short duration of effect. Perhaps because of the multiple nature of its airway effects, the histamine challenge test has provided a good tool for investigating bronchial responsiveness in asthma, with its complex pathophysiology.

Other potential techniques for assessing infant airway responsiveness, the administration of nebulised distilled water and subfreezing air, have not yet been assessed in wheezy infants, although cold air challenge has been briefly reported in normal infants. ${ }^{14}$ It might be predicted that neither would have a strong effect if during nasal breathing the respired air is subjected to an efficient conditioning process.

In the absence of a control group of normal infants, can we conclude that the bronchial responsiveness found in this study was abnormal? The fact that two subjects had no response to any histamine dose implies that a $\mathrm{PC}_{30}$ VmaxFRC of less than $8 \mathrm{~g} / \mathrm{l}$ of histamine is not universal in infants. The purpose of this study was to establish the technique; clearly, a normal population must be studied to determine the relationship between $\mathrm{PC}_{30}$ and disease state.

The level of responsiveness in our subjects was similar to that found in older asthmatic children and, as in older subjects, we found no relationship between the level of baseline airway obstruction and bronchial responsiveness in individual patients. The mean data did, however, suggest a rough correlation between the degree of airway obstruction and the level of responsiveness for the whole population (fig 4).

One striking feature of the response of two subjects (Nos 4 and 5) was the increase in VmaxFRC that occurred at the lowest doses of histamine (table, fig 2). We have frequently seen similar apparent improvements in flow rates in older children (N M Wilson, $M$ Silverman, unpublished observations) at the lowest histamine concentrations. Change in airway compliance at concentrations of histamine too low to affect airway calibre could provide the explanation. A reduction in intrathoracic airway compliance ("stiffening" of the airway) without overt narrowing would tend to increase VmaxFRC. A significant fall in VmaxFRC has been observed in 18 wheezy infants given nebulised salbutamol. ${ }^{28} \mathrm{By}$ similar reasoning, salbutamol may have led to an increase in airway compliance without a commensurate increase in airway calibre.

In addition to causing airways obstruction, histamine inhalation may lead to impairment of gas exchange. Mild hypoxia has recently been shown to develop in normal adults during histamine challenge. ${ }^{29}$ Preliminary observations carried out since the completion of this study suggest that this may be the case in infants too, although in the present study none of the infants showed signs of respiratory dis- tress or became visibly hypoxic. Chloral hydrate induces a mild degree of sedation, from which infants recover rapidly when picked up at the end of the study. Appreciable discomfort would undoubtedly have caused arousal during the procedure. As a precaution, it would be wise to carry out transcutaneous oxygen monitoring during bronchial challenge tests in infants.

\section{CONCLUSIONS}

From a practical viewpoint, the tidal breathing method for administering nebulised histamine was effective. VmaxFRC measured by the pressure jacket was a simple technique that rarely disturbed the babies. The technique provided a safe means of measuring bronchial responsiveness in infants.

The reproducibility of the technique was considerably poorer in infants than a similar histamine challenge procedure in older children. ${ }^{17}$ Whether this reflects the inherent clinical variability of our patients or the technical limitations of the procedure in a noncooperative age group may be determined in future studies. In practice, the within day confidence limits of 1.8 doubling concentrations provide a sufficient degree of sensitivity to allow useful clinical research to be performed.

The study of the natural history of reversible airways disease in infancy should now be feasible. Such observations, together with the pharmacological modification of bronchial responsiveness in infancy, may lead to a better understanding of the mechanisms and possible lines of treatment of wheezy infants.

We thank $\mathrm{Mr}$ Norman Levy and $\mathrm{Mr}$ Jimmy Messenger for their skilled mechanical and electrical assistance. Financial support was provided by the Asthma Research Council, Hammersmith and Queen Charlotte's Hospitals' Special Health Authority, and Allen and Hanburys Limited.

\section{References}

1 Neijens HJ, Duiverman EJ, Kerrebijn KF. Bronchial responsiveness in children. Ped Clin North Am 1983;30:829-46.

2 Silverman M, Wilson NM. Bronchial responsiveness in children: a clinical view. In: Milner AD, Martin J, eds. Neonatal and pediatric respiratory medicine. London: Butterworths, 1985. (International Medical Review Series.)

3 Boushay HA, Holtzman MJ, Sheller JR, Nadel JA Bronchial hyperreactivity. Am Rev Respir Dis 1980;121:389-413.

4 Boushay HA, Holtzman MJ. Experimental airway inflammation and hyperreactivity. Am Rev Respir Dis 1985;131:312-3. 
5 Silverman M. Bronchodilators for wheezy infants? Arch Dis Child 1984;59:84-7.

6 Benoist MR, Volanthen MC, Rufin P, Jean R. Apport des tests de provocation bronchique chez le nourrisson. Respiration 1981;42(suppl):51-2.

7 Gutkowski P, Kowalski J. Zentrale Atemregulation im bronchialen Provokationtest bei Sauglingen und Kleinkindern mit obstruktive Bronchitis. Atemw Lungenkronkh Jahrgang 1984;10:517-21.

8 Stocks $\mathrm{J}$. The functional growth of the lung during the first year of life. Early Human Development 1977;1:285-309.

9 Mygind N. Mediators of nasal allergy. $J$ Allergy Clin Immunol 1982;70:149-59.

10 Taussig LM, Landau LI, Godfrey S, Arad I. Determinants of forced expiratory flow in newborn infants. J Appl Physiol 1982;53:1220-7.

11 Silverman M, Prendiville A, Green S. Partial expiratory flow-volume curves in infancy: technical aspects. Bull Eur Physiopathol Respir 1986;22:257-62.

12 Godfrey S, Bar-Yishay E, Arad I, Landau LI, Taussig LM. Flow volume curves in infants with lung disease. Pediatrics 1983;72:517-22.

13 Beardsmore CS, Maayan Ch, Bar-Yishay E, Godfrey S. Flow-pressure looping during plethysmography in wheezy infants. Pediatr Pulmonol 1985;1:27-32.

14 Geller DE, Morgan WS, Cota KA, Taussig LM. Response of maximal respiratory flow (V́maxfRC) to breathing cold, dry air (CDA) in normal infants [abstract]. Am Rev Respir Dis 1985;131:A256.

15 Cartier A, Malo J-L, Begin P, Sestier M, Martin RR. Time course of the bronchoconstriction induced by inhaled histamine and methacholine. J Appl Physiol 1983;54:821-6.

16 Cockroft DW, Killian DN, Mellow JJA, Hargreaves FE. Bronchial reactivity to inhaled histamine: a method and a clinical survey. Clin Allergy 1977;7:235-43.

17 Hariparsad D, Wilson N, Dixon C, Silverman M. Reproducibility of histamine challenge tests in asthmatic children. Thorax 1983;38:258-60.
18 Stocks J, Levy NM, Godfrey S. A new apparatus for the accurate measurement of airway resistance in infancy. J Appl Physiol 1977;43:155-9.

19 Stocks J, Thompson A, Silverman M. The numerical analysis of pressure-flow curves in infancy. Pediatr Pulmonol 1985;1:19-26.

20 Dab I, Alexander F. On the advantages of specific airway resistance. Pediatr Res 1978;12:878-81.

21 Godfrey S, Beardsmore CS, Maayan C, Bar-Yishay E. Can thoracic gas volume be measured in infants with airways obstruction? Am Rev Respir Dis 1986; 133:245-51.

22 England SJ, Ho V, Zamel N. Laryngeal constriction in normal humans during experimentally induced bronchoconstriction. J Appl Physiol 1985;58:352-6.

23 Higgenbottam T. Narrowing of glottis opening in humans associated with experimentally induced bronchoconstriction. J Appl Physiol 1980;49:403-7.

24 Loring SH, Drazen JM, Smith JC, Hoppin FG. Vagal stimulation and aerosol histamine increase hysteresis of lung recoil. J Appl Physiol 1981;52:477-84.

25 Tien YK, Elliot EA, Mead J. Variability of the configuration of maximum expiratory flow-volume curves. J Appl Physiol 1979;46:565-70.

26 Martinez F, Morgan WJ. Time constant analysis of partial expiratory flow volume (PEFV) curves in normals and infants with bronchopulmonary dysplasia or bronchiolitis [abstract]. Am Rev Respir Dis 1985; 131:A262.

27 Juniper EF, Syty-Goloa M, Hargreave FE. Histamine inhalation tests: inhalation of aerosol via a face mask versus a valve box with mouthpiece. Thorax 1984;39:556-7.

28 Prendiville A, Green S, Silverman M. Paradoxical response to salbutamol in wheezy infants. Thorax 1987;42:86-91.

29 Gray B, Barnes B, Nyeko C, Marquis A. Changes in transcutaneous oxygen and carbon dioxide in response to histamine bronchial challenge [abstract]. Thorax 1986;41:246. 